\title{
Antihypertensive Effects of Continuous Oral Administration of Nattokinase and Its Fragments in Spontaneously Hypertensive Rats
}

\author{
Mitsugu Fujita, ${ }^{*, a}$ Katsunori Ohnishi, ${ }^{b}$ Shinsaku TaKaoka, ${ }^{b}$ Kazuya Ogasawara, ${ }^{b}$ \\ Ryo FuKUYAMA, ${ }^{a}$ and Hiromichi NAKAMUTA ${ }^{a}$ \\ ${ }^{a}$ Laboratory of Pharmacology, Department of Pharmaceutical Sciences, Faculty of Pharmaceutical Sciences, Hiroshima \\ International University; 5-1-1 Hirokoshingai, Kure, Hiroshima 737-0112, Japan: and ${ }^{b}$ Japan Bio Science Laboratory \\ Co., Ltd.; 1-1-59 Naka-hozumi, Ibaraki, Osaka 567-0034, Japan. \\ Received April 30, 2011; accepted August 12, 2011; published online August 18, 2011
}

To determine whether the antihypertensive effect of nattokinase is associated with the protease activity of this enzyme, we compared nattokinase with the fragments derived from nattokinase, which possessed no protease activity, in terms of the effect on hypertension in spontaneously hypertensive rats (SHR). In the continuous oral administration test, the groups were given a basic diet alone (control), the basic diet containing nattokinase $(0.2,2.6 \mathrm{mg} / \mathrm{g}$ diet) or the basic diet containing the fragments derived from nattokinase $(0.2,0.6 \mathrm{mg} / \mathrm{g}$ diet $)$. The group fed the basic diet containing high-dosage nattokinase $(2.6 \mathrm{mg} / \mathrm{g}$ diet) showed significant reductions in systolic blood pressure (SBP), diastolic blood pressure (DBP) and plasma fibrinogen level, compared with control group and no influence on activities of renin and angiotensin-converting enzyme (ACE, EC 3.4.15.1), and plasma angiotensin II level in the renin-angiotensin system. The treatment of the basic diet containing high-dosage fragments $(0.6 \mathrm{mg} / \mathrm{g}$ diet) significantly decreased SBP, DBP and plasma angiotensin II level in plasma but the treatment did not influence on plasma fibrinogen level. These results suggest that nattokinase and its fragments are different from each other in the mechanism to reduce hypertension. Nattokinase, retained its protease activity after absorbance across the intestines, may decrease blood pressure through cleavage of fibrinogen in plasma. The fragments, which absorbed as nattokinase-degradation products, prevents the elevation of plasma angiotensin II level to suppress hypertension.

Key words nattokinase; nattokinase fragment; blood pressure; angiotensin II; fibrinogen level

Natto is a traditional soybean-fermented food in Japan and contains nattokinase. Nattokinase is composed of total 275 amino acid residues and exhibits high homology with the subtilisins which are serine protease from Bacillus subtilis. ${ }^{1)}$ Comparing the steady-state kinetic parameters for the cleavage of fibrinogen and cross-linked fibrin by nattokinase with that of plasmin, the $K_{\mathrm{m}}$ value for cleavage of cross-linked fibrin by nattokinase was $1 / 12.5$ of that of plasmin, whereas the $K_{\mathrm{m}}$ value for cleavage of fibrinogen by nattokinase was similar to that of plasmin. ${ }^{2)}$ In addition, the thrombolytic activity of nattokinase was stronger than plasmin on the chemically induced thrombosis model in rat. ${ }^{3)}$ Therefore, nattokinase has been well known as a strong fibrinolytic and thrombolytic agent.

Recently, Kim et al. tried to test the effect of nattokinase on blood pressure with the large number of subjects (86 participants) with pre-hypertension or stage 1 hypertension and the result showed reduction in systolic blood pressure (SBP) and diastolic blood pressure (DBP) by nattokinase supplementation. ${ }^{4}$ The result of this trial has supported that nattokinase supplementation may be beneficial for hypertension. However, the mechanism by which nattokinase prevents hypertension has not been revealed yet, particularly whether the protease activity of this enzyme is needed. Proteins are, in general, decomposed into peptides or amino acids under the action of digestive enzymes such as trypsin, chymotrypsin and carboxypeptidase in the intestines. On the other hand, a previous study using rats has shown that nattokinase, escaped from the action of digestive enzymes, is absorbed from the small intestine and cleaves fibrinogen directly in plasma. ${ }^{5)}$

We investigate the effects of nattokinase (NK) and the fragments derived from nattokinase (FNK) on blood pres- sure, the renin-angiotensin system, and plasma fibrinogen level of SHR in the continuous oral administration test to determine whether the antihypertensive effect of nattokinase is associated with the protease activity of this enzyme.

\section{MATERIALS AND METHODS}

Nattokinase and the Fragments Derived from Nattokinase NSK-SD, provided by Japan Bio Science Laboratory (Osaka, Japan), is spray-dried powder of a compound of the cultural extract made from fermentation by Bacillus subtilis natto and dextrin as a stabilizer. The cultural extract was subjected to filtration to remove impurities of low molecular weight. As shown in lane 2 in Fig. 1, the fraction of NSK-SD contained a major protein (which dominated over $90 \%$ of proteins detected on reverse phase (RP)-HPLC by use of protein $\mathrm{C} 4$ column) and two minor proteins $(43,27 \mathrm{kDa})$. It was confirmed that NSK-SD contains nattokinase as the major protein by $\mathrm{N}$-terminal sequencing. The amount of nattokinase in NSK-SD was $3.4 \% \mathrm{w} / \mathrm{w}$ in a measurement. The measurement was performed by EnSpire ${ }^{\mathrm{TM}}$ Alpha (Perkin Elmer, MA, U.S.A.) according to AlphaLISA ${ }^{\circledR}$ assay development Guide and using AlphaLISA acceptor beads, Streptavidin-coated Alpha donor beads, and anti-nattokinase polyclonal antibody. This polyclonal antibody, purified Protein G column, was prepared by immunizing male New Zealand White rabbit with the purified nattokinase, and the preparation was entrusted in Keari (Osaka, Japan). The fragments derived from nattokinase were acquired by heating of NSK$\mathrm{SD}$ at $121^{\circ} \mathrm{C}$ in an autoclave. As shown in lane 3 in Fig. 1, nattokinase was decomposed into peptides by heating, and molecular weights of the all peptides were estimated to be 


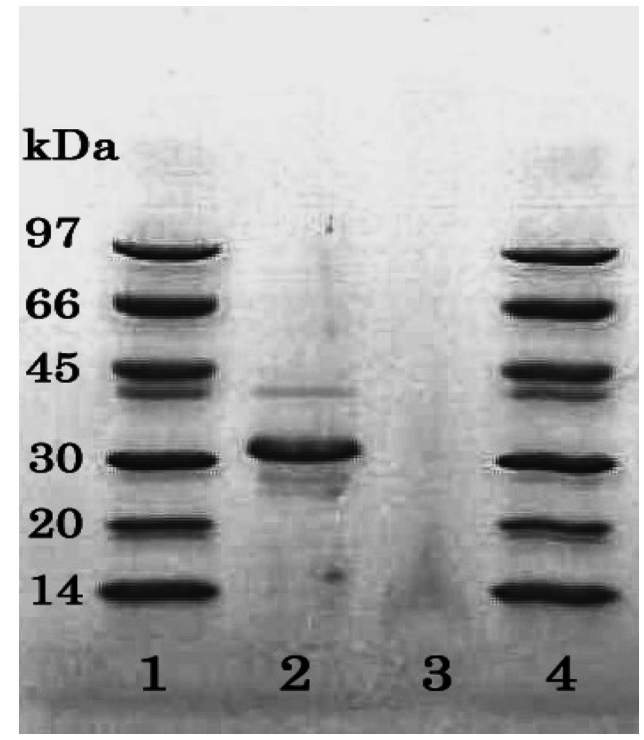

Fig. 1. Electrophoretic Patterns of Nattokinase and Fragments Derived from Nattokinase in a $8-25 \%$ Linear Polyacrylamide Gradient Gel under Non-reducing Condition

Lanes 1 and 4, protein molecular weight marker; lane 2, NSK-SD (nattokinase); lane 3 , heat-treated NSK-SD (fragments derived from nattokinase).

below $14 \mathrm{kDa}$ using a molecular weight protein standard (GE healthcare U.K., Buckinghamshire, England) on sodium dodecyl sulfate-polyacrylamide gel electrophoresis (SDSPAGE) under non-reducing condition.

Diets A regular rodent laboratory diet CE-2 was purchased from CLEA Japan (Tokyo, Japan) and was used as the basic diet. We entrusted the preparations of both the basic diet containing nattokinase and the basic diet containing the fragments derived from nattokinase to CLEA Japan. The diets containing 0.2 and $2.6 \mathrm{mg}$ per gram diet of nattokinase were prepared to replace $0.6 \%$ and $7.5 \%$ of CE- 2 with NSK$\mathrm{SD}$, respectively. Fibrinolytic activities of the basic diet containing 0.2 and $2.6 \mathrm{mg}$ nattokinase were 89.2 and $1160 \mathrm{FU}$ (fibrin degradation unit) per gram diet, respectively. FU was measured according to the method of measurement of nattokinase activity, ${ }^{6}$ provided by Japan Health Food and Nutrition Food Association. The diets containing 0.2 and $0.6 \mathrm{mg}$ per gram diet of the fragments derived from nattokinase were prepared to replace $0.6 \%$ and $1.8 \%$ of CE- 2 with the heattreated NSK-SD. These special feed had no fibrinolytic activity.

Animals The experimental protocol and animal care method in all the experiments were approved by the Experimental Animal Committee at Hiroshima International University. Eight-week-old male spontaneously hypertensive rats (SHR/Izm) were purchased from Shimizu Laboratory Supplies (Kyoto, Japan). The animals were housed three in each cage with the temperature and humidity of the laboratory set at $23 \pm 1{ }^{\circ} \mathrm{C}$ and $55 \pm 5 \%$, respectively. The laboratory was dark from 8:00 p.m. to 8:00 a.m. For a week, the animals were given free access to water and a basic diet (CE-2) to acclimatize the new environment. Before the continuous oral feeding test was started, SHR were accommodated to a tail cuff apparatus controlled by a computer (model MK-2000, Muromachi Kikai, Kyoto, Japan), measuring systolic blood pressure (SBP) and diastolic blood pressure (DBP) 3 times weekly between 1:30 p.m. and 5:00 p.m. for 3 weeks. Body weights from SHR were measured 3 times weekly between 1:00 p.m. and 1:30 p.m. for 3 weeks.

Protocol of the Experiment After 3 weeks of accommodation to the blood pressure monitor, animals (12-weekold SHR) were randomly divided into 5 groups to average the initial DBP and body weight and treated for 4 weeks as follows: fed the basic diet as control group $(C, n=18)$, fed the basic diet containing nattokinase $(0.2 \mathrm{mg} / \mathrm{g}$ diet $)$ as low-NK diet group (NK-L, $n=9$ ), fed the basic diet containing nattokinase $(2.6 \mathrm{mg} / \mathrm{g}$ diet) as high-NK diet group (NK-H, $n=9)$, fed the basic diet containing the fragments $(0.2 \mathrm{mg} / \mathrm{g}$ diet $)$ as low-NK fragments diet group (FNK-L, $n=9$ ), and fed the basic diet containing nattokinase $(0.6 \mathrm{mg} / \mathrm{g}$ diet $)$ as high-NK fragment diet group (FNK-H, $n=9$ ). SHR divided into each group were housed three per cage throughout the experiment. The SBP and DBP were measured once weekly between 1:30 p.m. and 5:00 p.m. Body weight and remaining food in each cage were measured 3 times weekly between 1:00 p.m. and 1:30 p.m. The amount of diet consumed in each cage was estimated by subtracting the weight of remaining food from the amount premeasured 2 or $3 \mathrm{~d}$ earlier. On $2 \mathrm{~d}$ prior to beginning of treatment, blood sample $(800 \mu \mathrm{l})$ was collected with heparin from the tail vein of rat anesthetized with ether in order to measure renin activity, angiotensin-converting enzyme (ACE) activity and angiotensin II level. On the last day of the test, $4 \mathrm{ml}$ of blood sample was collected with heparin from the inferior vena cava of rat anesthetized with ether in order to measure renin activity, ACE activity, angiotensin II level and fibrinogen level. The blood samples were immediately centrifuged at $2000 \times \boldsymbol{g}$ for $20 \mathrm{~min}$ at $4{ }^{\circ} \mathrm{C}$ to obtain plasma samples. The obtained plasma samples were stored at $-80^{\circ} \mathrm{C}$ until being measured for the levels and the activities.

Measurement of Blood Pressure The SBP and DBP from SHR were determined by tail cuff method without heating. ${ }^{7)}$ The rats were supported in an acrylic holder and maintained for $15 \mathrm{~min}$ in a temperature-controlled quiet room. The SBP and DBP from tail artery were measured using the tail cuff apparatus and values are presented as the average of three consecutive measurements.

Measurement of Blood Biochemistry Plasma angiotensin II was quantitated by a commercial kit (Angiotensin II EIA Kit, SPIbio, Monigny le Bretonneux, France). The kit used to quantify the plasma fibrinogen level employed a quantitative competitive enzyme immunoassay technique (AssayMax Rat Fibrinogen ELISA Kit, Assaypro, MO, U.S.A.). Plasma Renin activity was measured by a renin measurement kit (SensoLyte 520 Renin Assay kit, AnaSpec, Fremont, CA, U.S.A.). Plasma ACE activity was measured according to a method based on the detection of amount of 3hydroxybutyrate (3-HB), cleaved from 3-hydroxybutyrylGly-Gly-Gly (3HB-GGG) by both ACE and aminoacylase, with 4-[3-(4-iodophenyl)-2-(4-nitrophenyl)-2H-5-tetrazolio]1,3-benzene disulfonate sodium salt (WST-1). ${ }^{8}$ The measurement was done using the materials enclosed in ACE kitWST (Dojindo, Kumamoto, Japan) except for the enzyme A vial. The ACE activity of plasma sample was determined by the standard curve $(0-0.2 \mathrm{U} / \mathrm{ml})$ generated using ACE from rabbit lung (Sigma, MO, U.S.A.).

Statistical Analysis Each value is expressed as mean \pm S.E.M. For multiple comparisons, one-way analysis of vari- 
ance (1-way ANOVA) was performed, and then the statistical significance of differences between the control group (the $\mathrm{C}$ group) and each treatment group were analyzed by Dunnett's test (for parametric data). Non-parametric data were analyzed by the Kruskal-Wallis test followed by steel's test for posthoc comparison between the $\mathrm{C}$ group and each treatment group. Statistical significance was assumed at $p<0.05$. Calculations were made with the help of a commercially available statistical package (Social Survey Research Information Co., Ltd., Tokyo, Japan).

\section{RESULTS}

Diet Consumption and Body Weight Gain Table 1 shows the average value of the diet consumption and body
Table 1. Diet Consumption and Body Weight Gain of Rats in the Experimental Groups

\begin{tabular}{lccccc}
\hline \hline & $\mathrm{C}$ & NK-L & NK-H & FNK-L & FNK-H \\
\hline $\begin{array}{c}\text { Diet consumption } \\
(\mathrm{g} / \text { cage/d) } \\
\text { Body weight gain } \\
(\mathrm{g} / \mathrm{d})\end{array}$ & $55.6 \pm 0.7$ & $58.0 \pm 0.4$ & $54.8 \pm 0.7$ & $59.4 \pm 0.6^{* *}$ & $59.2 \pm 1.0^{*}$ \\
& $1.12 \pm 0.06$ & $1.31 \pm 0.06$ & $0.98 \pm 0.07$ & $1.18 \pm 0.07$ & $1.10 \pm 0.08$
\end{tabular}

Animals were divided into the following 5 groups: basic diet (C), basic diet containing $0.2 \mathrm{mg}$ nattokinase per gram diet (NK-L), basic diet containing $2.6 \mathrm{mg}$ nattokinase per gram diet $(\mathrm{NK}-\mathrm{H})$, basic diet containing $0.2 \mathrm{mg}$ fragments from nattokinase per gram diet (FNK-L), and basic diet containing $0.6 \mathrm{mg}$ fragments from nattokinase per gram diet (FNK-H). SHR divided into each group were housed 3 per cage throughout the experiment. Data are means \pm S.E.M. $* p<0.05$, $* * p<0.01$ : compared with the C group.
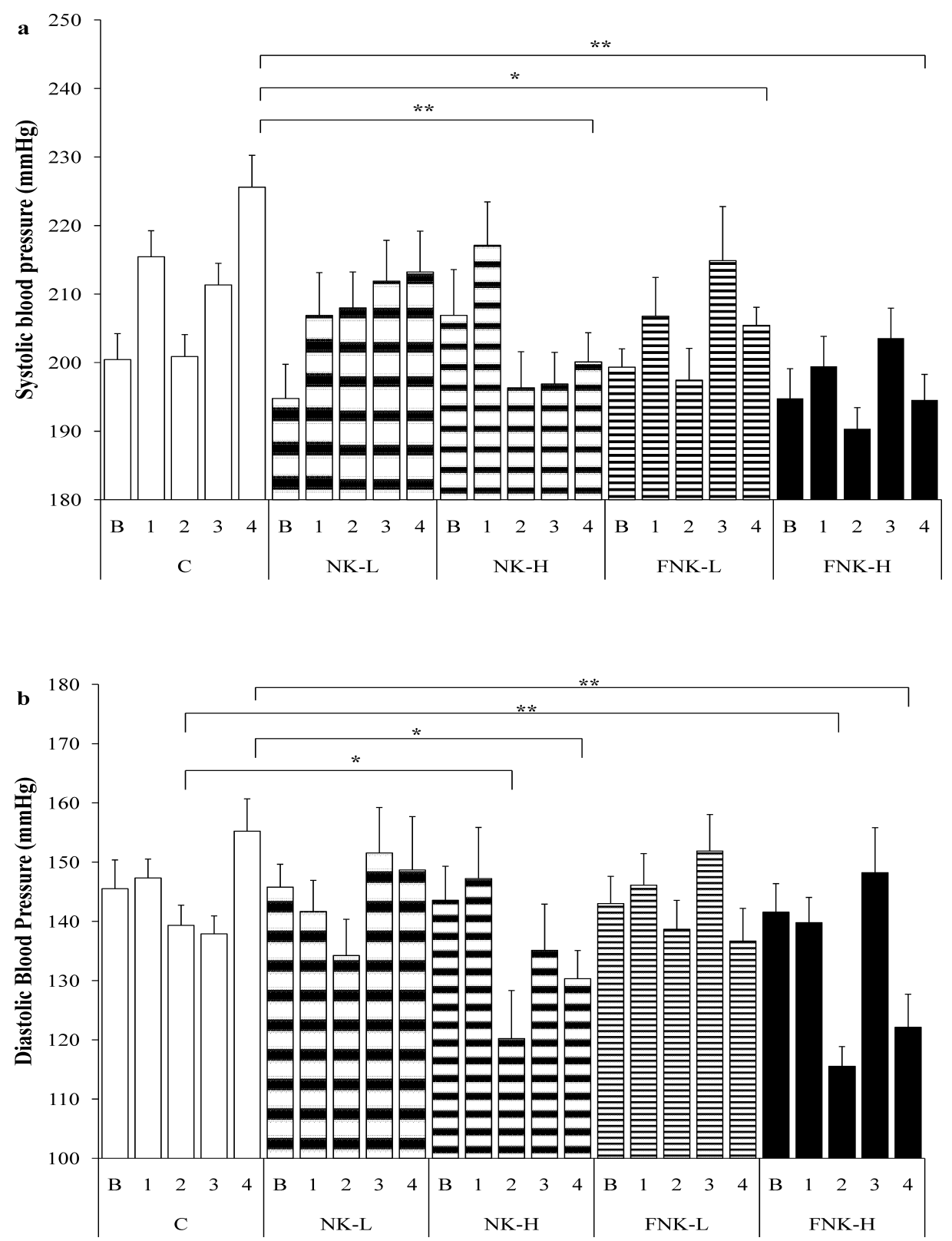

Fig. 2. Effects of the Continuous Oral Feeding of Nattokinase and the Fragment Derived from Nattokinase on Systolic (a) and Diastolic Blood Pressure (b) in SHR

Animals were divided into the following 5 groups: basic diet (C), basic diet containing $0.2 \mathrm{mg}$ nattokinase per gram diet (NK-L), basic diet containing $2.6 \mathrm{mg}$ nattokinase per gram diet (NK-H), basic diet containing $0.2 \mathrm{mg}$ fragments from nattokinase per gram diet (FNK-L), and basic diet containing $0.6 \mathrm{mg}$ fragments from nattokinase per gram diet (FNK-H). Blood pressures were measured on $2 \mathrm{~d}$ prior to beginning of treatment (baseline: B) and week 1, 2, 3 and 4 after the beginning of treatment. Each column represents the mean \pm S.E.M. $* p<0.05, * * p<0.01$ : significant difference from the $\mathrm{C}$ group at each week. 
weight gain of rats for 4 weeks after the beginning of treatment in the continuous oral administration test. Each average value of the diet consumption in the FNK-L and FNK-H groups was significantly higher than that of the $\mathrm{C}$ group. However, the body weight gain in each treatment group (NKL, NK-H, FNK-L and FNK-H) was not significantly different from that of the $\mathrm{C}$ group.

Effects of Nattokinase (NK) and the Fragment Derived from Nattokinase (FNK) on Blood Pressure Figure 2 shows the SBP and the DBP of the experimental groups on baseline (B) and week 1, 2, 3 and 4 after the beginning of treatment. In the $\mathrm{C}$ group, the SBP increased by 25 to $225.6 \pm 4.6 \mathrm{mmHg}$ in the 4 th week over the baseline (Fig. 2a). In the NK-L group, the SBP increased by 18.5 to $213.2 \pm$ $6.0 \mathrm{mmHg}$ in the 4th week over the baseline and the significant difference from the $\mathrm{C}$ group was not observed from week 1 to 4 . The SBP in the 4th week was significantly lower in rats of the NK-H, FNK-L and FNK-H groups than that in rats of the $\mathrm{C}$ group and the value in rats of the NK-H group decreased over the baseline.

The DBP of the 5 groups at the baseline were about $145 \mathrm{mmHg}$ (Fig. 2b). The DBP from week 1 to 4 in rats of the NK-L and FNK-L groups did not significantly change in comparison with the $\mathrm{C}$ group. The DBP in the 2 nd and 4th week in rats of the NK-H and FNK-H groups decreased over the baseline and was significantly lower than those in rats of the $\mathrm{C}$ group.

Effects of NK and FNK on the Renin-Angiotensin System Table 2 shows the changes of renin activity, ACE activity and angiotensin II level from the baseline to 4 weeks after the beginning of treatment in the oral administration test. The renin activities ( $\%$ of baseline) were similar in all experimental groups and there were no elevation of the activities from the baseline to the end of experiment. ACE activity and angiotensin II level, respectively, were elevated $146.1 \pm 9.0$ and $264.2 \pm 31.1 \%$ at the end of experiment to the baseline in the $\mathrm{C}$ group. The elevation of ACE activity in each treatment group was not different from that in the $\mathrm{C}$ group. The increase in angiotensin II level (139.2 $\pm 34.8 \%)$ was significantly lower in rats of the FNK-H group than that in rats of the $\mathrm{C}$ group.
Effects of NK and FNK on Plasma Fibrinogen Concentration Plasma fibrinogen concentrations of all groups at the end of experimental period were shown in Fig. 3. The plasma fibrinogen concentrations ( $\mathrm{mg} / \mathrm{ml}$ plasma) were as follows: the C group 4.22 \pm 0.16 , the NK-L group 4.01 \pm 0.25 , the NK-H group $3.50 \pm 0.18$, the FNK-L group 3.92 \pm 0.18 and the FNK-H group 3.86 \pm 0.17 . In comparison with the $\mathrm{C}$ group, plasma fibrinogen concentration observed in the NK$\mathrm{H}$ group significantly decreased.

\section{DISCUSSION}

Nattokinase has been investigated as a strong fibrinolytic enzyme in vitro and in vivo. ${ }^{1-3,5)}$ Recent study has reported that oral administration of supplement containing nattokinase decreases both systolic blood pressure and diastolic blood pressure from hypertension patients. ${ }^{4)}$ However, the mechanism by which nattokinase prevents hypertension has still to be found out. In this study, we compared the effect of nattokinase (NK) on hypertension in SHR with that of the fragments derived from nattokinase (FNK) to examine whether the protease activity of this enzyme is required to reduce blood pressure.

In our study, the SBP in the 4th week and the DBP in the 2nd and 4th week in rats of the NK-H group decreased over

Table 2. Effects of Nattokinase (NK) and Fragments Derived from Nattokinase (FNK) on the Renin-Angiotensin System in SHR

\begin{tabular}{lccccc}
\hline \hline & C & NK-L & NK-H & FNK-L & FNK-H \\
\hline $\begin{array}{c}\text { Renin activity } \\
(\% \text { of baseline })\end{array}$ & $94.6 \pm 3.8$ & $103.8 \pm 1.0$ & $97.3 \pm 3.6$ & $113.8 \pm 8.5$ & $101.4 \pm 1.8$ \\
$\begin{array}{c}\text { ACE activity } \\
(\% \text { of baseline })\end{array}$ & $146.1 \pm 9.0$ & $175.9 \pm 15.2$ & $166.9 \pm 25.4$ & $139.9 \pm 12.5$ & $166.5 \pm 17.1$ \\
$\begin{array}{c}\text { Ang II level } \\
(\% \text { of baseline })\end{array}$ & $264.2 \pm 31.1$ & $206.6 \pm 38.5$ & $208.2 \pm 24.4$ & $244.5 \pm 55.1$ & $139.2 \pm 34.8^{*}$ \\
\hline
\end{tabular}

Animals were divided into the following 5 groups: basic diet $(\mathrm{C})$, basic diet containing $0.2 \mathrm{mg}$ nattokinase per gram diet (NK-L), basic diet containing $2.6 \mathrm{mg}$ nattokinase per gram diet $(\mathrm{NK}-\mathrm{H})$, basic diet containing $0.2 \mathrm{mg}$ fragments from nattokinase per gram diet (FNK-L), and basic diet containing $0.6 \mathrm{mg}$ fragments from nattokinase per gram diet (FNK-H). The blood samples were collected on $2 \mathrm{~d}$ prior to beginning of treatment (baseline) and the end of experimental period. Each value at the end of experimental period is expressed the value of baseline as $100 \%$. Data are means \pm S.E.M. $* p<0.05$ : compared with the $\mathrm{C}$ group

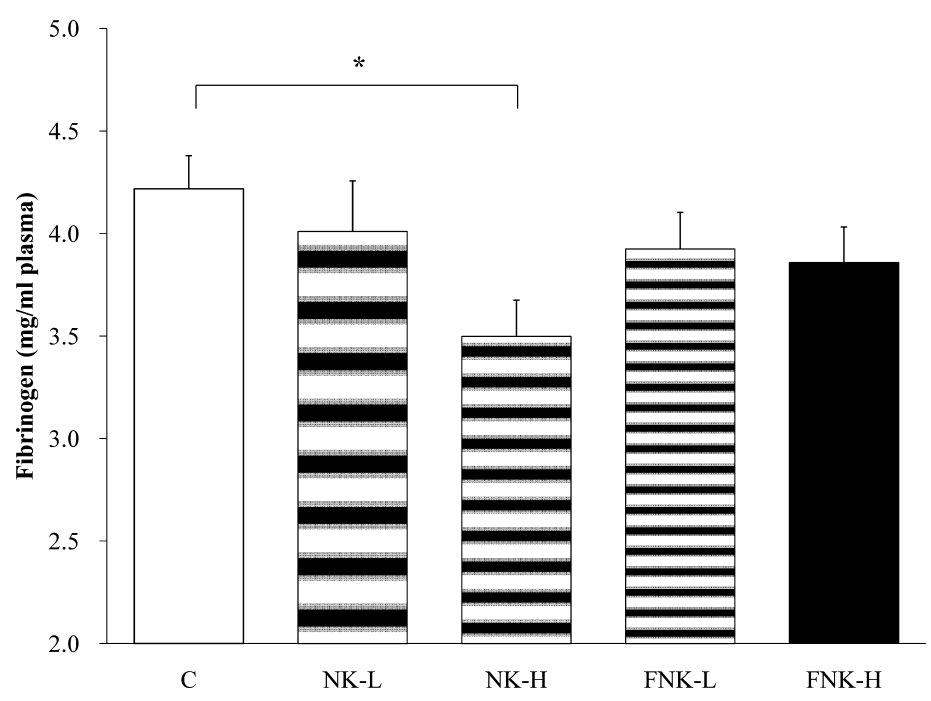

Fig. 3. Effects of the Continuous Oral Feeding of Nattokinase and the Fragment from Nattokinase on Plasma Fibrinogen Concentration in SHR The blood samples were collected on the end of experimental period. Each column represents the mean \pm S.E.M. $* p<0.05$ : significant difference from the C group. 
the baseline and a similar trend was observed in those of FNK-H group (Fig. 2). This result shows that high-dose NK $(2.6 \mathrm{mg} / \mathrm{g}$ diet $)$ had roughly the same antihypertensive effect as high-dose FNK $(0.6 \mathrm{mg} / \mathrm{g}$ diet $)$. High-dose NK did not down-regulate the parameters such as renin activity, ACE activity and angiotensin II level in the renin-angiotensin system (Table 2), but it significantly decreased the plasma fibrinogen level in comparison with the basic diet (Fig. 3). On the other hand, the high-dose FNK significantly inhibited the elevation of angiotensin II in the renin-angiotensin system (Table 2) and had no effect on the plasma fibrinogen level (Fig. 3). These data indicate that there is major difference between nattokinase and its fragments in their mechanism to reduce hypertension.

Peripheral vascular resistance, which is a key factor of arterial blood pressure, is influenced by changes in the red blood cell (RBC) aggregation and plasma protein concentration. ${ }^{9,10)}$ The elevation of diastolic blood pressure with maturation of SHR from 3 weeks old to 12 weeks old is related to the increase of both plasma viscosity and RBC aggregation, which are determined by the increase of both fibronectin and fibrinogen in mature SHR. ${ }^{10)}$ In the early stage of hypertension development of 3-week-old SHR, the increase of fibronectin may cause the increase of both plasma viscosity and $\mathrm{RBC}$ aggregation. ${ }^{10)} \mathrm{RBC}$ aggregation results from an increase in plasma fibrinogen ${ }^{11)}$ and is caused by both nonspecific and specific fibrinogen binding to erythrocyte membranes. ${ }^{12)}$ Furthermore, Mchedlishvili et al. has reported that RBC aggregation may be an important factor responsible for the elevation of systemic arterial pressure in human beings. ${ }^{13)}$ These findings provide evidence that plasma viscosity and $\mathrm{RBC}$ aggregation are major factors to increase peripheral vascular resistance in hypertension, and the plasma concentrations of fibrinogen and fibronectin affect the two major factors.

Pais et al. have reported that nattokinase decreased RBC aggregation and whole blood viscosity in vivo study. ${ }^{14)}$ The previous animal experiment of our group has indicated that nattokinase, absorbed from the small intestine, remains in an intact form and cleaves plasma fibrinogen directly. ${ }^{5)}$ In the present study, the antihypertensive effect of NK-H in SHR is associated with the reduction of plasma fibrinogen level (Figs. 2, 3). Therefore nattokinase absorbed as the intact form from the intestines may reduce the blood pressures in SHR by cleaving plasma fibrinogen.

Our results show that the antihypertensive effect of FNK$\mathrm{H}$ is related to inhibiting the elevation of angiotensin II in the renin-angiotensin system. Angiotensin II acts directly on vascular smooth muscle to raise blood pressure and is known as a vasopressor hormone. Therefore, FNK reduces blood pressures in SHR by preventing the elevation of angiotensin II.

The production of angiotensin II from angiotensinogen in the renin-angiotensin system requires the participation of the enzymes such as renin and ACE. Renin produces angiotensin I from angiotensinogen and ACE converts angiotensin I to angiotensin II. There are numerous studies of the ACEinhibitory and renin-inhibitory peptides obtained from several foods such as sesame, ${ }^{15}$ sour milk, ${ }^{16,17)}$ wheat germ, ${ }^{18}$ casein $^{19)}$ and soybean whey protein. ${ }^{20)}$ Some studies have demonstrated that the small peptides, possessing the renininhibitory or ACE-inhibitory activity, were derived from food and exhibit antihypertensive effect in experimental animals. ${ }^{15,17-21)}$ The tri-peptide Val-Ala-Pro derived from $\operatorname{casein}^{19)}$ and soybean whey protein ${ }^{20)}$ is known as ACE-inhibitory and antihypertensive peptide. This sequence corresponds to residues $\mathrm{Val}^{84}-\mathrm{Ala}^{85}$-Pro $^{86}$ of nattokinase. ${ }^{1)}$ The dipeptide Tyr-Tyr derived from royal jelly is found to inhibit renin activity and lowers blood pressure in SHR. ${ }^{21}$ ) This sequence corresponds to residues $\mathrm{Tyr}^{262}-\mathrm{Tyr}^{263}$ of nattokinase. ${ }^{1)}$ Adibi has reported that the small peptides were easily absorbed through the intestines and remained their intact form. ${ }^{22)}$ Consequently, FNK which was easily decomposed into small peptides under the action of digestive enzymes in the intestines could have down-regulated the renin-angiotensin system in SHR. However, both the renin and ACE activities in SHR were not inhibited by low-dose and highdose FNK as shown in Table 2. In our study, the underlying mechanism by which FNK prevents the elevation of angiotensin II was not clarified well; thus further studies on the mechanism are required to clarify the discrepancy of our results.

There are several reports mentioned that Bacillus subtilis produces and secretes enzymes such as subtilisin, ${ }^{23)}$ metalloprotease, ${ }^{24)} \mathrm{Epr}^{25)} \mathrm{Mpr}{ }^{26)} \mathrm{Vpr}^{27)}$ bacillopeptidase $\mathrm{F}^{28,29)}$ and $\beta$-glucanase. ${ }^{30)}$ As shown in Fig. 1, NSK-SD contained minor proteins $(43,27 \mathrm{kDa})$ as impurities except for nattokinase $(31 \mathrm{kDa})$. In N-terminal sequencing, the $27 \mathrm{kDa}$ protein is assumed to be a degradation product which was removed peptide from $\mathrm{N}$-terminus of $\beta$-glucanase (unpublished data). $\beta$-Glucanase, which generates glucose from glucan, is not protease and does not affect fibrinogen, renin and ACE in the present study. On the other hand, the $43 \mathrm{kDa}$ protein in NSK$\mathrm{SD}$ is postulated to be bacillopeptidase $\mathrm{F}$ because the $43 \mathrm{kDa}$ protein has both a similar molecular weight on SDS-PAGE and a similar isoelectric point to bacillopeptidase F. Bacillopeptidase F, derived from Bacillus subtilis natto, digests fibrin clot directly in $0.1 \mathrm{mg} / \mathrm{ml}$ and prolongs plasma coagulation time (APTT and PT) in rat with intraduodenal administration $\left(5-250 \mathrm{mg} / \mathrm{kg}\right.$ body weight). ${ }^{29}$ ) Nattokinase also digests cross-linked fibrin directly in $0.02 \mathrm{mg} / \mathrm{ml}^{2)}$ and prolongs the plasma coagulation time in parallel with fibrinogen degradation in rat with intraduodenal administration ( $80 \mathrm{mg} / \mathrm{kg}$ body weight). ${ }^{5}$ These previous reports suggest that the fibrinolytic and antithrombotic effets of nattokinase is similar or superior to those of bacillopeptidase F. Bacillopeptidase $\mathrm{F}$ has the residues $\mathrm{Val}^{101}-\mathrm{Ala}^{102}-\mathrm{Pro}^{103}$ which corresponds to the ACE-inhibitory tri-peptide Val-Ala-Pro and does not have the renin-inhibitory di-peptide Tyr-Tyr. ${ }^{29)}$ Furthermore, NSK-SD contains extremely small amount of bacillopeptidase F compared to nattokinase. Thus, we believe that the $43 \mathrm{kDa}$ impurity is not enough to affect on the findings in our study.

In conclusion, nattokinase, no matter whether its intact form or its fragments, is absorbed from the intestines and reduces hypertension in SHR. Nevertheless, there are different mechanisms on antihypertensive effect depending on the form in oral administration. Nattokinase, retained its protease activity, may lower blood pressure through the decrease of blood viscosity by cleaving plasma fibrinogen. The fragments obtained from nattokinase suppresses hypertension via down-regulation of plasma angiotensin II level. 
Acknowledgments This study was supported by financial aid from Japan Bio Science Laboratory Co., Ltd. The authors wish to thank Mr. Kouichi Sugimoto, Ms. Urara Mochiduki and Ms. Minami Yao for their excellent technical assistance.

\section{REFERENCES}

1) Fujita M., Nomura K., Hong K., Ito Y., Asada A., Nishimuro S., Biochem. Biophys. Res. Commun., 197, 1340-1347 (1993).

2) Fujita M., Ito Y., Hong K., Nishimuro S., Fibrinolysis, 9, 157-164 (1995).

3) Fujita M., Hong K., Ito Y., Fujii R., Kariya K., Nishimuro S., Biol. Pharm. Bull., 18, 1387-1391 (1995).

4) Kim J. Y., Gum S. N., Paik J. K., Lim H. H., Kim K. C., Ogasawara K., Inoue K., Park S., Jang Y., Lee J. H., Hypertens. Res., 31, 1583-1588 (2008).

5) Fujita M., Hong K., Ito Y., Misawa S., Takeuchi N., Kariya K., Nishimuro S., Biol. Pharm. Bull., 18, 1194-1196 (1995).

6) Ogasawara K., Food Style 21, 12, 79-83 (2008).

7) Kubota Y., Umegaki K., Kagota S., Tanaka N., Nakamura K., Kunitomo M., Shinozuka K., Biol. Pharm. Bull., 29, 1756-1758 (2006).

8) Lam H., Shimamura T., Manabe S., Ishiyama M., Ukeda H., Anal. Sci., 24, 1057-1060 (2008).

9) Zannad F., Stoltz J. F., J. Hypertens., 10 (Suppl. 5), S69-S78 (1992)

10) Lominadze D., Joshua I. G., Schuschke D. A., Am. J. Hypertens., 11, $784-789$ (1998).

11) Letcher R. L., Chien S., Pickering T. G., Laragh J. H., Hypertension, 5, 757-762 (1983).

12) Lominadze D., Dean W. L., FEBS Lett., 517, $41-44$ (2002).

13) Mchedlishvili G., Gobejishvili L., Beritashvili N., Microvasc. Res., 45 , $233-242$ (1993).
14) Pais E., Alexy T., Holsworth R. E. Jr., Meiselman H., Clin. Hemorheol. Microcirc., 35, 139-142 (2006).

15) Nakano D., Ogura K., Miyakoshi M., Ishii F., Kawanishi H., Kurumazuka D., Kwak C. J., Ikemura K., Takaoka M., Moriguchi S., Iino T., Kusumoto A., Asami S., Shibata H., Kiso Y., Matsumura Y., Biosci. Biotechnol. Biochem., 70, 1118-1126 (2006).

16) Nakamura Y., Yamamoto N., Sakai K., Okubo A., Yamazaki S., Takano T., J. Dairy Sci., 78, 777-783 (1995).

17) Nakamura Y., Yamamoto N., Sakai K., Takano T., J. Dairy Sci., 78, 1253-1257 (1995).

18) Matsui T., Li C. H., Osajima Y., J. Pept. Sci., 5, 289-297 (1999).

19) Maruyama S., Mitachi H., Tanaka H., Tomizuka N., Suzuki H., Agric. Biol. Chem., 51, 1581-1586 (1987).

20) Yonekura M., Ichimura T., Nishikawa M., Soy Protein Res. Japan, 8, 97-102 (2005).

21) Sultana A., Nabi A. H., Nasir U. M., Maruyama H., Suzuki K. M., Mishima S., Suzuki F., Int. J. Mol. Med., 21, 677-681 (2008).

22) Adibi S. A., J. Clin. Invest., 50, 2266-2275 (1971).

23) Kawamura F., Doi R. H., J. Bacteriol., 160, $442-444$ (1984).

24) Uehara H., Yamane K., Maruo B., J. Bacteriol., 139, 583-590 (1979).

25) Sloma A., Ally A., Ally D., Pero J., J. Bacteriol., 170, 5557—5563 (1988).

26) Sloma A., Rudolph C. F., Rufo G. A. Jr., Sullivan B. J., Theriault K A., Ally D., Pero J., J. Bacteriol., 172, 1024-1029 (1990).

27) Sloma A., Rufo G. A. Jr., Theriault K. A., Dwyer M., Wilson S. W., Pero J., J. Bacteriol., 173, 6889-6895 (1991).

28) Sloma A., Rufo G. A. Jr., Rudolph C. F., Sullivan B. J., Theriault K. A., Pero J., J. Bacteriol., 172, 1470-1477 (1990).

29) Omura K., Hitosugi M., Zhu X., Ikeda M., Maeda H., Tokudome S., J. Pharmacol. Sci., 99, 247-251 (2005).

30) Murphy N., McConnell D. J., Cantwell B. A., Nucleic Acids Res., 12, 5355-5367 (1984). 